\title{
THE DRIFT SCALE HEATER TEST AT YUCCA MOUNTAIN, NEVADA
}

Mark T. Peters', William J. Boyle², Robin N. Datta', Ned Z Elkins ${ }^{3}$, Robert N. Yasek ${ }^{2}$, Ralph

A. Wagner', and Douglas J. Weaver'. 1. Woodward-Clyde Federal Services, 1180 Town

Center Drive, Las Vegas, NV 89134; 2. U.S. Department of Energy, YMSCO, Las Vegas, NV 89134; 3. Los Alamos National Laboratory, 1180 Town Center Drive, Las Vegas, NV 89134.

The Drift Scale Heater Test (DST) is an integral part of the program of testing and studies being conducted by the U.S. Department of Energy to evaluate the suitability of Yucca Mountain, Nevada as a site of a deep geologic repository for the permanent disposal of spent nuclear fuel and high-level nuclear waste. The DST is a large-scale, in situ thermal test to be conducted over nearly a decade in the Exploratory Studies Facility at Yucca Mountain (Figure 1).

The overall objective of the DST is to acquire a more in-depth understanding of the physical processes that will occur in the rock surrounding the emplaced waste. There are four principal processes of concern: thermal, mechanical, hydrological, and chemical. These processes will be intensified because of the decay heat from the emplaced waste and their interaction or coupling. An understanding of these coupled processes is essential for the assessment of the long-term (over thousands of years) performance of the repository.

The DST consists of a $47.5 \mathrm{~m}$ long, $5 \mathrm{~m}$ diameter drift to be heated by 9 canister heaters, $1.7 \mathrm{~m}$ diameter and $4.6 \mathrm{~m}$ long, placed on the floor of the drift (Figures 1 and 2 ). Each canister 
heater can generate a maximum of $15 \mathrm{~kW}$. The drift cross-section and the canister heaters are approximately the sizes of drifts and waste packages being considered for the repository. To simulate the heat that would come from adjacent drifts in the repository and thus, to provide better test boundary conditions, 25 rod heaters, referred to as wing heaters, are inserted into horizontal boreholes on each sidewall of the drift (Figure 2). The $10 \mathrm{~m}$ long wing heaters have inner and outer segments that can generate $1145 \mathrm{~W}$ and $1719 \mathrm{~W}$, respectively. The heater outputs can be varied over a range of 10 to $100 \%$ of the designed capacity. The heated length of the drift will be isolated by a thermal bulkhead. An Observation Drift, parallel to the Heated Drift, and a Connecting Drift are constructed along the periphery of the test block (Figures 1 and 2). Approximately 3300 meters of boreholes are drilled from these three drifts. into the test block (Figure 3). Approximately 3500 measuring devices of various types are installed in these boreholes.

As the rock is heated and subsequently cooled, temperature will be measured by resistance temperature devices (RTDs) and thermocouples; displacements in the rock will be measured by multiple point borehole extensometers and convergence meters; moisture content of the rock will be monitored by neutron logging, ground penetrating radar (GPR), and electric resistivity tomography (ERT); relative humidity, temperature, and pressure will be measured in sections of boreholes isolated by inflated packers; changes in rock mass permeability will be measured by conducting air-injection tests in these isolated borehole chambers; REKA probes will measure thermal conductivity and thermal diffusivity; samples of water and gas will be collected by water absorbing pads and gas sampling ports in SEAMIST liners installed in boreholes; microseismic emissions, if any, will be monitored; a remotely operated video and infrared camera system will image periodically along the entire length of the Heated Drift. The $12.5 \mathrm{~m}$ length at the far (west) end of the Heated Drift includes a ground support system 
composed of a cast-in-place concrete liner. Response of the concrete liner/rock system to the heat will be monitored by strain gages and convergence meters.

An approximately 6000 channel automated data collection system will record measurements on an hourly basis, which will generate an estimated 40 gigabytes of data over the life of the test. Other measurements, such as ERT, neutron logging, GPR, and microseismic monitoring, will be recorded using independent data acquisition systems.

During the heating phase of the DST, planned to last for four years, the drift wall temperature is planned to reach $200^{\circ} \mathrm{C}$ and will be maintained there for a sufficient period to ensure hydrological and chemical processes are properly observed. Over 10,000 cubic meters of rock will be heated to above $100^{\circ} \mathrm{C}$, while over 200,000 cubic meters of rock is expected to be heated above ambient temperatures. Approximately 800 cubic meters of water in the rock is expected to be mobilized by the heat.

Based on laboratory studies, prior in situ thermal testing, observations of natural geothermal phenomena, and knowledge of other physical processes, scientists have developed conceptual models of the various near field processes. These models were the basis for scoping calculations to assist in the design of the test configuration and instrumentation plans. A suite of characterization measurements have been made to determine various properties of the rock in the test block. Employing these block-specific rock parameter values in the existing conceptual models, predictive analyses of the Drift Scale Test were performed to forecast the measurements to be made at various points in time during the test. Periodic comparative analyses of the predicted and observed measurements are expected to provide insights into the heat-driven near field phenomena, leading to refinement of the conceptual models. The 
refined models will be used to predict the measurements during subsequent periods of the test. This predictive-corrective process is expected to converge into near field process models for use in the assessment of repository performance, the level of confidence in which will be acceptably high.

The work was sponsored by the U.S. Department of Energy, Yucca Mountain Site Characterization Office under contract number DE-AC01-91RW00134 with TRW Environmental Safety Systems, Inc. 


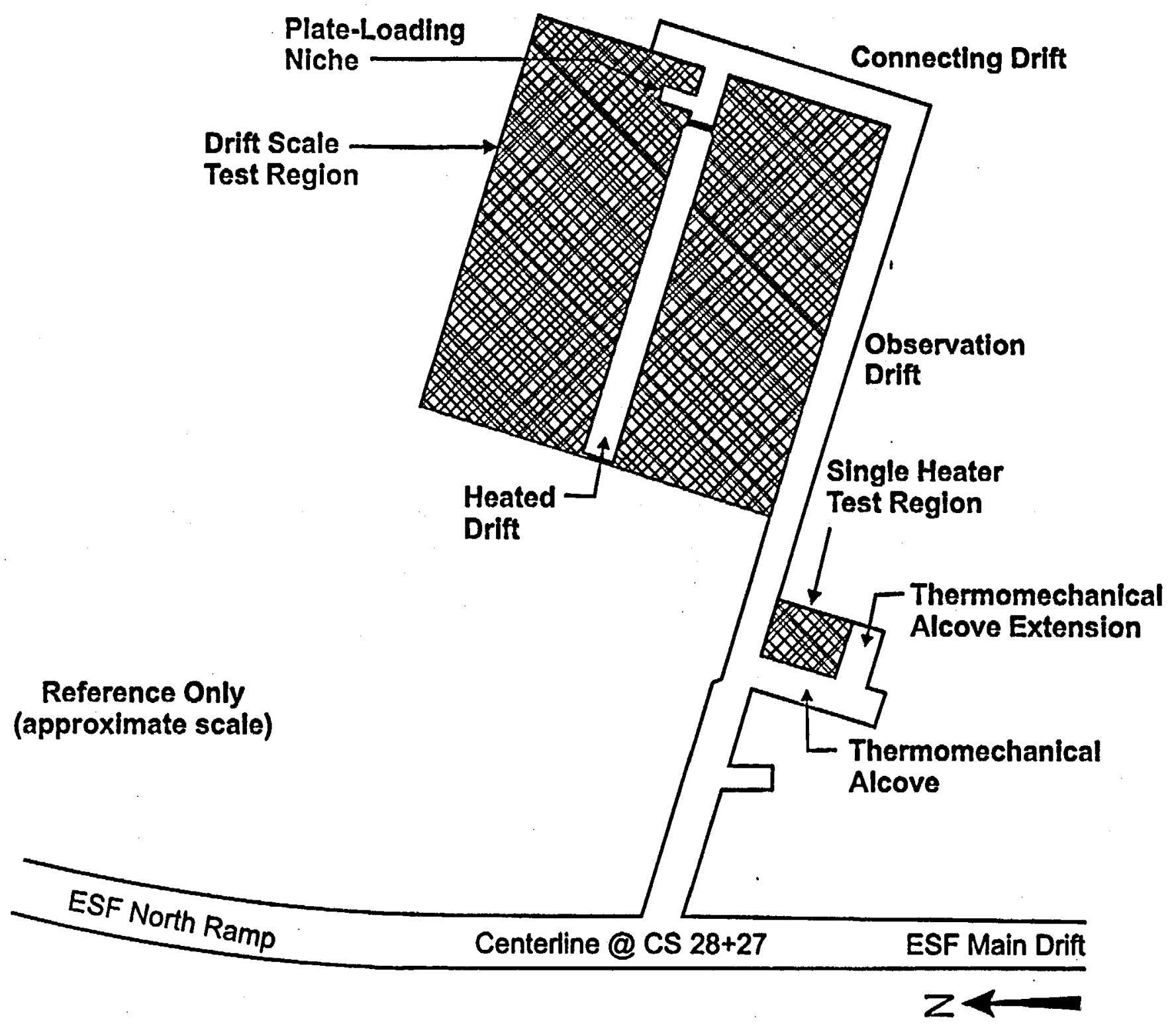

Figure 1 


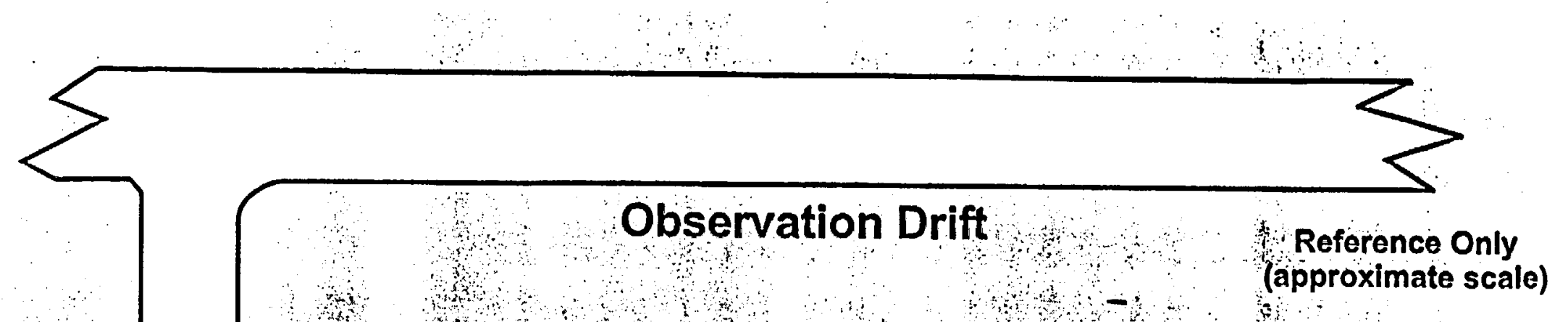

\section{Connecting
Drift ,Wing Heater (typ.)}$$
\text { . }
$$ 


\section{REFERENCE ONLY \\ (APPROXIMATE SCALE: $1 \mathrm{CM}=3 \mathrm{M}$ )}

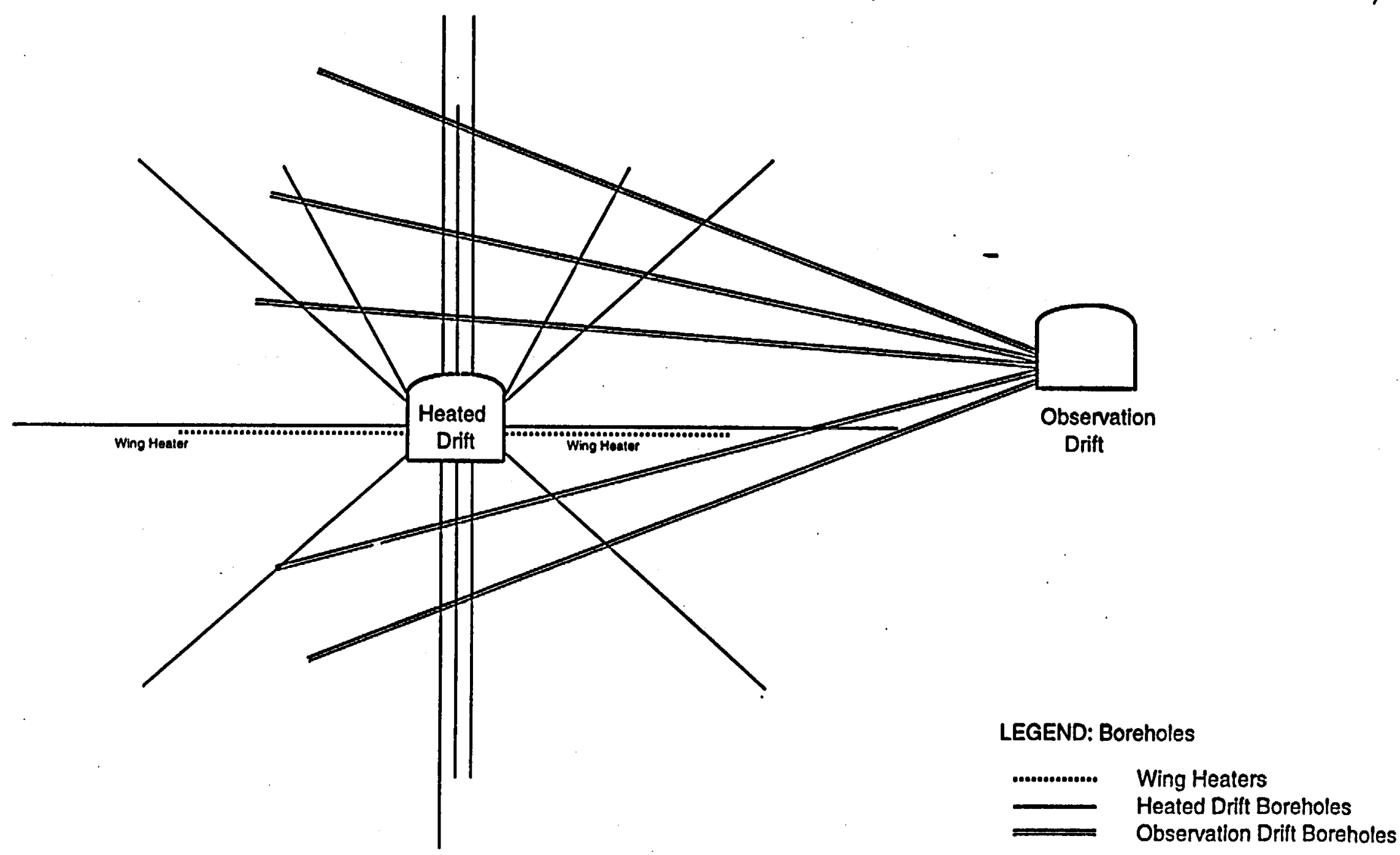

Figure 3 